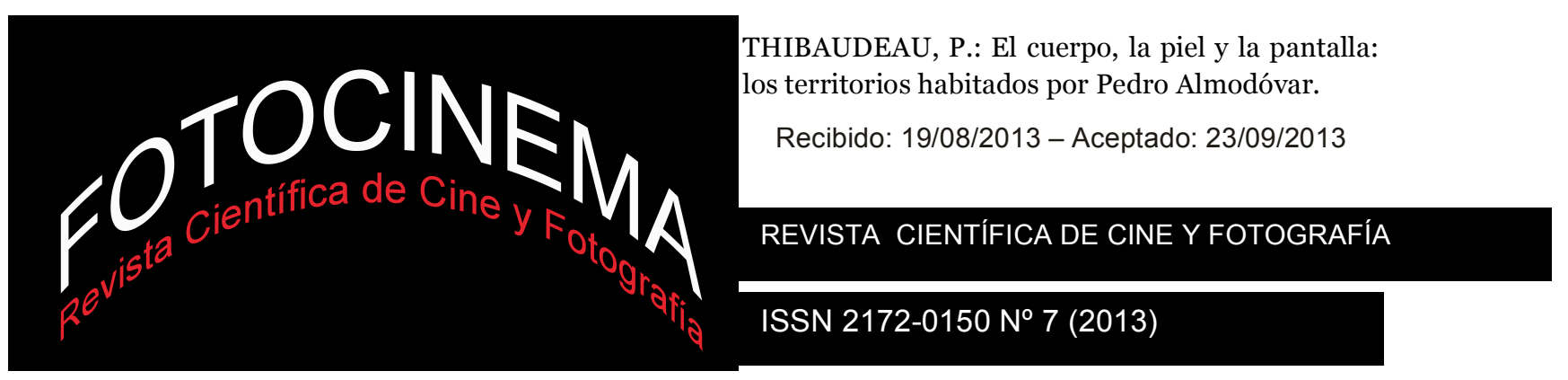

\title{
EL CUERPO, LA PIEL Y LA PANTALLA: LOS TERRITORIOS HABITADOS POR PEDRO ALMODÓVAR*
}

\section{BODY, SKIN AND SCREEN: THE TERRITORIES INHABITED BY ALMODOVAR}

\section{Resumen:}

En este artículo se estudian las implicaciones que tiene en La piel que habito la cuestión del cuerpo y de su territorio. Las interrogaciones sobre la identidad del sujeto, presentes en toda la filmografía de Pedro Almodóvar, alcanzan aquí su culminación concerniendo no solamente a la identidad del individuo sino también a la de las obras.

El juego de correspondencias instaurado por Pedro Almodóvar entre la cirugía plástica y la costura, entre la piel y el tejido, se prolonga en la relación plástica y visual que se establece entre la pantalla y el cuadro pictórico para desembocar en el trabajo del cine como arte del ensamblaje y la sutura. Para explorar las múltiples pistas que ofrece la película, la autora se vale de referencias a la mitología, al concepto de "Yo-Piel" creado por Didier Anzieu y a la dimensión háptica de la imagen desarrollada por Gilles Deleuze.

\section{Pascale Thibaudeau \\ Université Paris 8}

\section{Abstract:}

In this article are studied the implications of the body's question and its territory in The Skin I Live In. The interrogations about the identity of the subject, which are present in the whole filmography of Pedro Almodovar, are reaching here their culmination point concerning not only the identity of the individual, but also the identity of the movies.

The concept of the cinematographic art as an assembling and seaming art is echoed in the plastic and visual relation that is established between screen and painting, as Pedro Almodovar institutes a matching game between plastic surgery and sewing, between skin and tissue.

To explore the multiple clues that offers the movie, the author uses references to mythology, to the concept of "I-Skin" developed by Didier Anzieu and to the haptic of pictures developed by Gilles Deleuze.

Palabras clave: Almodóvar ; La piel que habito ; Moi-Peau ; pintura ; mitología ; transtextualidad.

Keywords: Almodovar; The Skin I Live In; Moi-Peau; Painting; Mitology; Transtextuality.

\footnotetext{
* Texto traducido por Jean-Marc Suardi y la autora.
} 


\section{Introducción}

En el cine, algunas frases finales tienen la capacidad de abrir un territorio incierto, lleno de interrogantes para el espectador abandonado por la película ante un abismo. Algo parecido se produce al final del largometraje de Pedro Almodóvar, La piel que habito ${ }^{1}$, cuando Vicente, el cual lleva seis años desaparecido, entra en la tienda de ropa de su madre y ésta no lo reconoce porque, durante los años de su ausencia, Vicente se ha convertido en Vera. No sólo ha cambiado de sexo sino también de piel y de cara, y no por decisión propia sino porque ha sido víctima de una terrible venganza, comparable con las que en la Antigüedad concebían los dioses del Olimpo para castigar a los humanos.

Sin embargo, y pese a su metamorfosis, en el sentido ovidiano del término (el film se inscribe claramente dentro de una filiación mitográfica ${ }^{2}$ ), la chica se presenta ante la madre del desaparecido y murmura, en un último plano sobrecogedor: "Soy Vicente".

El fundido al negro que cierra el plano y el film sitúa, a la vez, a la madre frente al abismo de la revelación y al espectador ante una aporía que no deja de recordar la que se produce en Vértigo con la doble identidad del personaje femenino. Porque si Vera puede decir que es Vicente, su existencia misma y su presencia en la tienda demuestran simultáneamente que Vicente ha dejado de ser.

El cineasta nos ha acostumbrado, a lo largo de su filmografía, a la presencia de personajes híbridos, en la frontera de los géneros masculino y femenino, seres imperfectos en perpetuo devenir3. Ya se trate de la envoltura, la ropa como segunda piel -con el travestismo- o del núcleo de la identidad sexual con la transexualidad-, Pedro Almodóvar parecía haber explorado las múltiples categorías posibles de configuraciones genéricas, al tiempo que reivindicaba abiertamente, por el tratamiento de los personajes, el derecho

\footnotetext{
${ }^{1}$ Libremente adaptado de la novela Mygale de Thierry Jonquet.

2 Bénédicte Brémard ha desarrollado el paralelismo entre el doble personaje de Vera-Vicente y el mito del silfo y de la silfida (Brémard, 2012).

3 Cuerpos-celacanto, eslabones intermediarios de una evolución inacabada, según la imagen propuesta por Jean-Claude Seguin (2009, 263-269).
} 
de cada uno a realizar sobre su propio cuerpo las modificaciones necesarias a la afirmación de sí mismo. Como tal, el monólogo de Agrado, frente al público del teatro, en Todo sobre mi madre, verdadero manifiesto queer, resulta particularmente evocador: "iMiren qué cuerpo! iTodo hecho a medida!" proclama, antes de dar el precio pormenorizado de las operaciones de cirugía plástica por las que pasó. Y concluye afirmando: "Cuesta mucho ser auténtica, señoras, y en estas cosas no hay que ser rácana. Porque una es más auténtica cuando más se parece a lo que ha soñado de sí misma".

Ahora bien, lo que hasta ahora aparecía como una elección libremente asumida -incluso en una película como La mala educación en la que la transexualidad es abordada de manera más sombría- se convierte aquí en uno de los peores castigos infligidos a un ser humano, consistiendo en quitarle todo lo que funda su identidad.

La piel que habito gira pues en torno a la cuestión del cuerpo y de su territorio, sea éste psíquico, social o fisiológico, y en torno a la cuestión de los límites entre lo propio y lo ajeno. Constituye así la suma de motivos e interrogaciones sobre la identidad, presentes en toda la filmografía de Pedro Almodóvar, y que parecen alcanzar aquí una suerte de culminación.

El breve resumen del film que sigue pretende reconstruir la intriga en su cronología, sin dar cuenta de la construcción elaborada del film que procede por flash-backs y saltos temporales (Thibaudeau, 2014).

Vicente trabaja en la tienda de su madre donde se dedica a "customizar" ropa de segunda mano y a intentar seducir a la dependienta, Cristina, quien lo rechaza porque no le gustan los hombres. Una tarde, acude a una boda donde conoce y seduce a Norma, hija del doctor Ledgard. Bajo los efectos del alcohol y de la droga, interpreta mal las reacciones de la chica y, ante su rechazo, forcejea con ella dejándola inconsciente antes de fugarse, espantado por su gesto. Tras esta agresión, Norma, ya traumatizada de niña por el suicidio de su madre ante sus ojos, termina de perder la razón y se suicida a su vez. Convencido de la culpabilidad de Vicente, el Doctor Ledgard lo rapta, lo secuestra y le hace sufrir numerosas operaciones como si fuera un animal 
de laboratorio. Lo transforma en mujer y experimenta en él tratamientos para injertarle una piel transgénica ultra resistente. Por último, le modifica la cara para que se parezca a su mujer difunta, Gal, y le quita hasta su nombre bautizándolo Vera, nombre cuya etimología no se le escapa a nadie. Reclusa en una habitación, Vera encuentra en la lectura, el yoga y la escultura los medios para no sucumbir a la locura y al aniquilamiento. Cuando se acaba la metamorfosis, le pregunta a Ledgard lo que piensa hacer con ella, consciente de que el odio que éste sentía por Vicente se fue transformando en fascinación por su criatura. En efecto, Ledgard se encuentra en un callejón sin salida porque no se resuelve a matar el fruto de su venganza que ha acabado subyugándole. Al día siguiente, Zeca, el hijo de Marilia, la vigilante de Vera, se introduce en la mansión y viola a ésta tomándola por Gal, su antigua amante. Ledgard lo sorprende in fraganti y lo mata, eligiendo perdonarle la vida a Vera que se entrega a él la misma noche jurándole fidelidad. Sin embargo, tras convencer a Ledgard de que no le traicionará y ganar su confianza, lo mata a él y a Marilia, huye de la mansión donde estuvo recluida durante seis años y se presenta ante su madre.

A lo largo de este resumen, hemos pasado de "él" a "ella" porque le resulta imposible al espectador seguir viendo en Vera al personaje de Vicente, a partir del momento en que cambia de cara, y el actor Jan Cornet deja lugar a la actriz Elena Anaya4. Sin embargo, sabemos que Vera no es sino lo que se ha vuelto Vicente, y que si éste ha desaparecido por completo, no por ello ha dejado de existir.

No intentaremos resolver aquí esta paradoja pero veremos a continuación lo que persiste de la identidad de Vicente en Vera. Nos interesaremos primero por la piel como territorio: a la vez envoltura, superficie y zona de intercambios, la piel es el lugar en el que se determina la relación del ser consigo mismo y con el mundo, como lo desarrolla el sicoanalista Didier Anzieu mediante la metáfora del Yo-piel que le permite establecer una correlación entre el funcionamiento de la piel y el del aparato psíquico. Las

4 También porque la construcción temporal nos presenta primero a Vera antes de descubrirnos quién fue en el pasado. 
tres funciones de base del Yo-piel combinan con las de la piel orgánica5: se trata de "una función de envoltura que contiene y unifica al Ser, una función de barrera protectora del psiquismo, una función de filtro de intercambios y de inscripción de las primeras huellas, función que hace posible la representación. A estas tres funciones corresponden tres figuraciones: el saco, la pantalla y el tamiz" (Anzieu 1985, 121). La referencia a la noción desarrollada por Anzieu no se utilizará para llevar a cabo un análisis del psiquismo de un personaje de ficción, aunque sea doble, sino para operar una articulación entre, por una parte, las diferentes modalidades de representación de la piel (desde las manipulaciones genéticas del Doctor Ledgard hasta la actividad artística de Vera, pasando por el trabajo de Vicente con la ropa), y, por otra parte, esos territorios que son la pintura y el cine.

\section{La piel y el tejido}

La piel transgénica que le ha sido transplantada se vuelve, para Vera, en el primer lugar de su reclusión, antes de la habitación donde está encerrada. Comprendemos que Ledgard tuvo que hacer varios ensayos antes de poner a punto la nueva piel y que, para injertarla fue necesario destruir la primera: "Ahora sí que es cierto que ya no habrá más quemaduras" le promete a Vera quien le responde: "Eso ya me lo dijiste hace un año". Sabemos que Gal, la mujer de Ledgard, fue víctima de un accidente de coche en el que resultó gravemente herida y que fue porque descubrió el reflejo de su cara desfigurada por lo que se tiró por la ventana. Ledgard, al crear, gracias a manipulaciones genéticas, una piel que resista a las quemaduras, cura en el cuerpo de Vera la piel de su mujer difunta, al tiempo que le da una cara en la que procura reproducir los rasgos de la desaparecida. Es decir que al destruir a Vicente se venga de la muerte de su hija, pero al crear a Vera reproduce a Gal (primera sílaba de Galatea) y cae en la trampa de su orgullo prometeano,

5 « [...] une fonction d'enveloppe contenante et unifiante du Soi, une fonction de barrière protectrice du psychisme, une fonction de filtre des échanges et d'inscription des premières traces, fonction qui rend possible la représentation. À ces trois fonctions correspondent trois figurations : le sac, l'écran, le tamis » (Anzieu 1985, 61-62). 
dispuesto a todo, hasta arriesgar su propia vida, para salvarla. Como Pigmalión, otro mito convocado, el doctor Ledgard esculpió a Vera según sus propios deseos, y, como Galatea surgida de la piedra, Vera salió de Vicente, emancipándose hasta el punto de que su creador olvidara la materia de la que estaba sacada.

La piel transgénica de Vera se desdobla en una segunda piel de tejido, un body primero negro y luego color carne, concebido para proteger la primera y

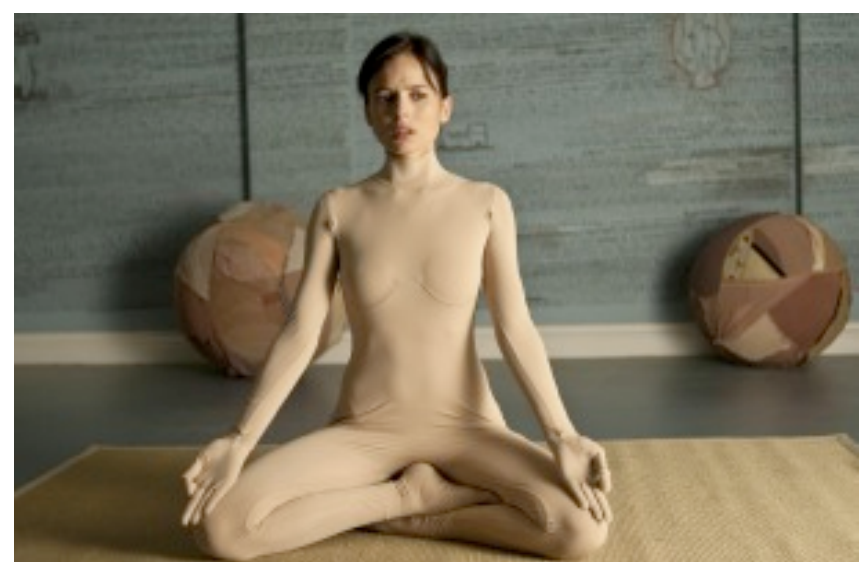
esperar que cicatrice del todo. Sobre este body, cuyas costuras son visibles [F 1$]$, pueden leerse las huellas de las operaciones y violencias impuestas al cuerpo que, sin embargo, permanecen invisibles: el único acto quirúrgico en verse es la sutura de una herida después de que Vera haya intentado degollarse a sí misma. No es baladí que este acto remita explícitamente, mediante la aguja, el hilo y las tijeras, a la costura.

El paralelo resulta obvio entre el textil y la epidermis cuando Vera se pone el body que tapa sus cicatrices. Antes vimos al cirujano preparando la piel en su laboratorio cortando y ensamblando fragmentos de piel sobre un maniquí, imagen que remite a la vez al corte de carnicería y al patrón de costura [F 2].

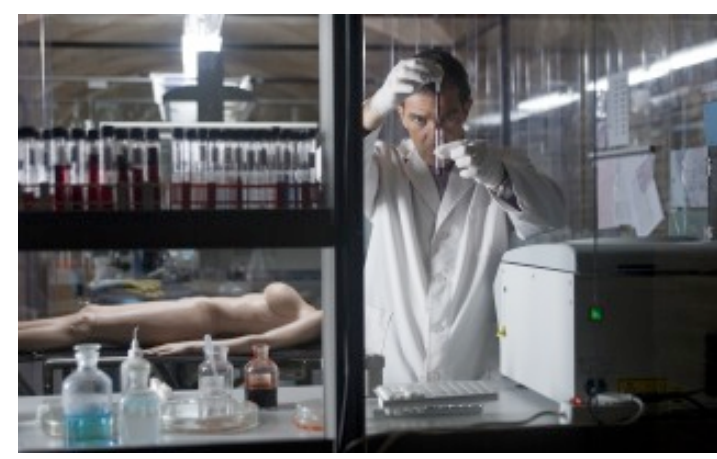
La piel es la primera ropa del cuerpo, así como cualquier vestimenta es una segunda piel, como explicita el body carne llevado por Vera. En este sentido, el hecho de que la madre de Vicente tenga una tienda de ropa usada no es nada casual: la tienda es el lugar donde estas pieles que son las ropas usadas pasan de un cuerpo a otro, y donde Vicente las reforma, creando nuevas a partir de 
antiguas; es ahí también donde queda sellado su destino por un cineasta demiurgo que nunca negó su afición a los trapos.

En efecto, antes de acudir a la fiesta donde va a cometer lo irreparable, Vicente le regala a Cristina un vestido pidiéndole que se lo pruebe, a lo que se niega ella diciendo: "Si tanto te gusta póntelo tú". Cuando Vera entra en la tienda seis años más tarde, lleva este mismo vestido, esta segunda piel y único vestigio físico del pasado, que le permite a Cristina identificar a Vicente en la mujer que tiene enfrente. «Cambiar de ropa para cambiar de ser, para crear otro cuerpo, otros límites... son las ropas las que crean los cuerpos. Ellas tejen un límite múltiple, una línea virtual entre yo y el otro, pero además entre yo y yo... Sí mismo como otro» escribía Jean-Claude Seguin (2009, 161) antes del estreno de este film que, no sólo viene a corroborar magistralmente el acierto de estas palabras, sino que lleva al límite extremo la propensión de los personajes almodovarianos a cambiar de piel.

El juego de correspondencias instaurado por Pedro Almodóvar entre la cirugía plástica y la costura, entre la piel y el tejido encuentra su prolongación en la actividad creadora a la que se dedica Vera en su habitación-cárcel. Esculpe bustos de plastilina en los que pega vendas de tejido recortadas de los vestidos que se niega primero a poner, desviando así los atributos de una feminidad impuesta ${ }^{6}$. Al fabricar estos figurines, retoma algunos gestos de Vicente cuando creaba y vestía los maniquíes en la tienda de su madre. El gesto creador parece ser, para Almodóvar, lo que persiste de la memoria íntima de un cuerpo cuya apariencia ha desaparecido. Por otra parte, es difícil no fijarse en la homología que establece el film entre la actividad manual de Vera y el trabajo de Ledgard sobre su cuerpo y su piel, una homología que da cuenta de la sublimación por el arte de un mecanismo de tipo proyectivo.

\footnotetext{
${ }^{6}$ Observemos que Norma rechaza del mismo modo la ropa que siente como una opresión. En el parque en el que pasea con Vicente, tira sus escarpines y su chaqueta exclamando: "Estoy harta de tanto tacón y de esta chaqueta. Me da claustrofobia tanto vestido. Por mí, iría todo el tiempo desnuda." Más tarde, tras ingresar en el hospital, el médico le explica a Ledgard que ya no soporta la ropa y que se la arranca.
} 
De hecho, las esculturas de Vera se inspiran abiertamente en la obra de Louise Bourgeois ya que es al ver un documental sobre la artista cuando vislumbra un medio para sobrevivir a su doble secuestro (en su habitación y en esta piel exógena). La referencia es explícita, se trate de las imágenes del film proyectado en la televisión, de los libros entrevistos, o de los agradecimientos insertados en los créditos finales: "Gracias a Louise Bourgeois, cuya obra no sólo me ha emocionado, sino que sirve de salvación al personaje de Vera". Al poner de manifiesto la función catártica y terapéutica del arte, Pedro Almodóvar coincide con la artista estadounidense cuya obra entera tiene como objetivo sublimar la angustia mediante su apropiación. ¿Acaso no escribió, en la parte alta de la instalación Precious liquid (1992), que se puede ver en el Centro Pompidou, "El arte es una garantía de salud mental"? Inscripción copiada por Vera en la pared de su habitación.

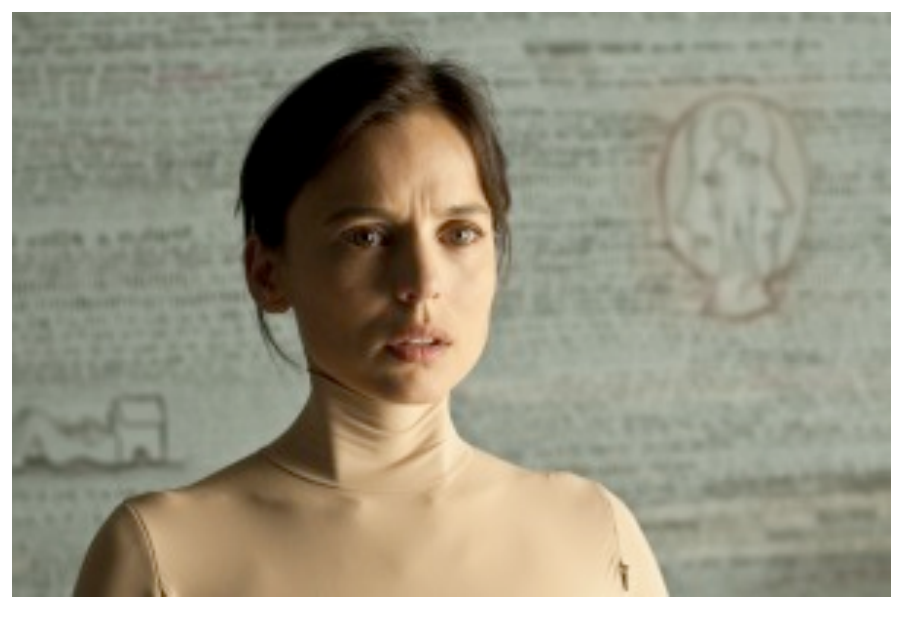

En efecto, cuando Ledgard le manda lápices cosméticos, en vez de maquillarse, Vera se pone a escribir en las paredes de su habitación [F 3] la fecha de cada uno de sus días de encierro, así como palabras y frases tales que:

"Respiro", "Sé que respiro", "El opio me ayuda a olvidar". Esta anexión del espacio de reclusión hace eco a los territorios que ocupa el arte bruto; entre otros se puede evocar el caso de Fernando Oreste Nannetti [F 4] que grabó durante nueve años, con la punta de la hebilla de su chaquetilla las paredes del hospital psiquiátrico de Volterra (Toscana) donde estaba internado. O también el de Jeannot, campesino del Béarn (Francia), quien grabó con un punzón, en letras mayúsculas, el suelo de madera de la habitación donde él 
mismo se había encerrado7 ${ }^{7}$ Al revestir las paredes de una piel de letras, Vera se apropia del territorio de su encierro, sea el que sea.

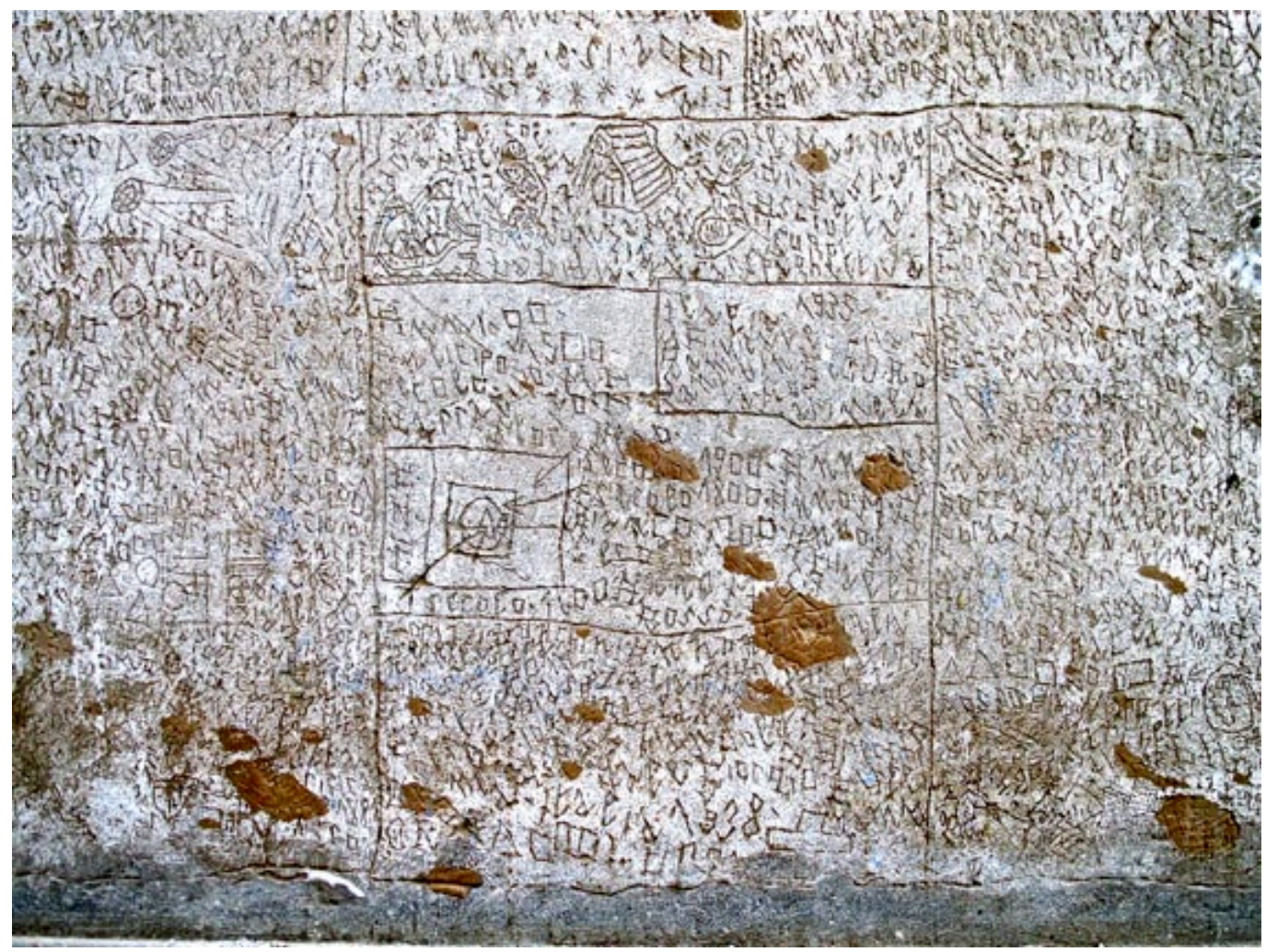

El famoso motivo de la mujer-casa de Louise Bourgeois, reproducido en medio de la pared cubierta de inscripciones ${ }^{8}$, es sin duda el símbolo ambivalente de esta apropiación, a la vez espacio de reclusión y espacio mental protegido. Un refugio íntimo al que se refiere también la profesora de yoga cuyas palabras transmite la televisión: "Tenéis que saber que hay un lugar en el que os podéis refugiar, un lugar que está en vuestro interior, un lugar al que nadie más tiene acceso, un lugar que nadie puede destrozar, que nadie puede destruir". Este territorio interior, este núcleo, es a la vez la identidad y la persistencia del ser hecha posible gracias a una memoria que Vera parecía, por un tiempo, haber perdido ("El opio me ayuda a olvidar" escribe) pero que, como hemos visto, se reactiva en los gestos. Así, de la

7 El "parqué de Jeannot" está expuesto en tres paneles, delante del hospital psiquiátrico Saint-Anne en París.

8 Cuando Vera vuelve a la tienda, en la última secuencia, un plano muestra su reflejo en el escaparate adornado con un papel pintado que representa un apiñamiento de casas de estilo arabizante, y cuyo grafismo apretado evoca las paredes cubiertas de escritura de la habitación de Vera. 
misma manera que para Louise Bourgeois el trabajo con el tejido y el hilo era una manera de volver a establecer el vínculo con la madre cuyo oficio era restaurar tapices, para Vera, el contacto con la materialidad del textil viene a ser también el modo de mantener un vínculo, el trabajo artístico haciendo las veces de restauración, de remiendo del lazo que estuvo cortado no sólo con la madre sino consigo misma/o.

Por otra parte, las imágenes de obras de Louise Bourgeois insertadas en el film recuerdan que sus creaciones de tela hacen coexistir a menudo los dos sexos entremezclándolos, exhibiendo el interior y el exterior de la organicidad humana mediante muñecas de trapo donde son visibles, como en el body de Vera, las costuras que reúnen las diferentes piezas. "En perpetua metamorfosis, -escribe Robert Storr-, las formas de Louise Bourgeois hacen el inventario de las permutaciones aparentemente inagotables de las oposiciones sexuales"9, borran los límites del género al tiempo que expresan diferentes modalidades del sufrimiento humano, de los miedos y de las pulsiones reprimidas. La referencia a la obra de esta artista trabaja pues en profundidad el film, no sólo como clave de elaboración del personaje de Vera, sino como encarnación de la práctica cinematográfica de Pedro Almodóvar como vamos a verlo interesándonos por la pintura.

\section{El cuadro y la pantalla}

"La piel es para el doctor Ledgard lo que el lienzo es para el pintor"10 afirma el cineasta, y de hecho le otorga, como en otros filmes, un sitio privilegiado a la cita pictórica en La Piel que habito. Lo que difiere tal vez de otras películas suyas, es la relación plástica y visual que en ésta se establece entre la pantalla y el cuadro. La inmensa mansión de Ledgard es adornada con obras contemporáneas (Jorge Galindo, Guillermo Pérez Villalta, Juan Uslé...) y dos reproducciones de cuadros de Tiziano basados en un tema mitológico: la Venus de Urbino y Venus y Cupido con un organista. Sendas reproducciones

9 "En perpétuelle métamorphose -escribe Robert Storr-, les formes de Louise Bourgeois inventorient les permutations apparemment inépuisables des oppositions sexuelles", (Storr, 1992).

10 "La peau est au Dr Ledgard ce que la toile est au peintre" (Duncan y Peiró, 2011, 385).

201 
están reproducidas en el rellano que da a la habitación en la que está encerrada Vera. Es precisamente en este mismo rellano donde Zeca, el hijo de Marilia, disfrazado de tigre, empieza a abusar de la cautiva [F 5], acontecimiento que remite a la vez a lo grotesco y a la violencia originarios y

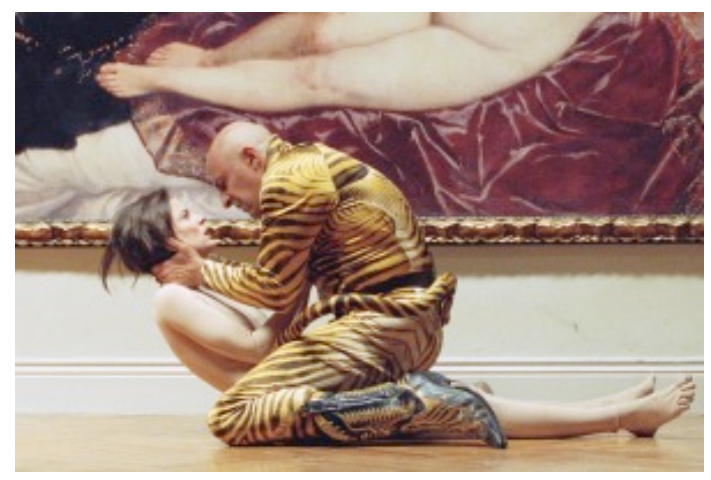
propios de la mitología grecolatina.

Pero la función de estos dos cuadros, que los historiadores del arte consideran como la matriz, con la Venus de Dresde de Giorgione, de la Venus del espejo de Velázquez, consiste sobre todo en asentar el film en la tradición de los desnudos pictóricos al establecer una correlación entre imagen pintada e imagen filmada. En efecto, cuando el doctor Ledgard entra en su habitación, lo primero que hace es encender la pantalla por la que vigila a Vera y contempla su obra. Más que una simple pantalla de control, como es el caso en la cocina, ésta se asemeja, por su formato apaisado, sus dimensiones y su localización, a la vez a un cuadro y a un espejo sin azogue por el que Ledgard puede envolver a Vera con la mirada, verla sin ser visto, lo que, recordémoslo aunque es obvio, funda la relación escópica del espectador con la imagen de cine. La pantalla secundaria se convierte aquí en el marco de otra escena que, entonces, se vuelve cuadro. Así, los planos de Vera en la pantalla convocan, sin citarla, la Venus del espejo de Velázquez como culminación de los cuadros de Tiziano vistos anteriormente, al tiempo que manifiestan el hechizo que la criatura ejerce sobre su creador y, más allá, sobre el espectador.

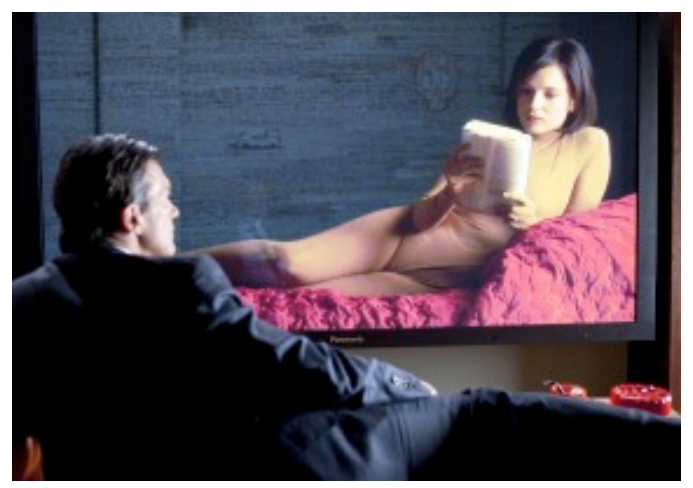

El espacio visual se vuelve a configurar por completo en torno a la pulsión escópica en la que se abisma Ledgard, llevándose con él, en tanto que delegado en la ficción, al espectador. En una de las secuencias en las que se le ve contemplando a Vera [F 6], se 
tumba frente a la pantalla en una posición exactamente simétrica, lo que crea un quiasmo visual en el que el médico parece mirarse en ella. La distancia entre el que está observando y la que está observada se desvanece y el zoom sobre la cara de Vera levantando la mirada hacia su secuestrador consagra la inversión producida por la pulsión. Le toca a Ledgard ser el cautivo; la proximidad de las habitaciones (son vecinas), y la interfaz de la pantalla señalan la reversibilidad del dispositivo, porque la vigilancia que él ejerce continuamente sobre Vera, por medio de cámaras, condiciona su propio cautiverio, sin contar que ella, al saberse filmada, comprende que puede a su vez hechizar a su secuestrador. Al hacer desaparecer a Vicente y crear a Vera, Ledgard se encerró a sí mismo dentro de un laberinto reflexivo del que no saldrá ileso, como avisa un plano oracular en el que la cara de Ledgard se refleja sobre la pantalla, al lado de su criatura. "En estos momentos íntimos comenta Pedro Almodóvar- de estrecha vigilancia, aunque Vera es la víctima, mana de su cara desmesurada un inmenso poder, mucho más fuerte que el del doctor Ledgard que la está contemplando con éxtasis" (Duncan y Peiró, 2011, 382) ${ }^{11}$; un poder hipnótico similar al del dispositivo cinematográfico ${ }^{12}$.

Aparte de esta pantalla-cuadro, las pantallas son numerosas en el film, ya se trate de pantallas de control, de vigilancia o de televisión. Cumplen una función narrativa importante ya que transmiten informaciones que hacen progresar la intriga y ponen en contacto a los personajes (Marilia decide abrirle a Zeca cuando reconoce, en la pantalla del interfono, la mancha de nacimiento de su hijo); por otra parte, Vera encuentra la fuerza para sobrevivir a su doble secuestro gracias a unos programas de televisión. De hecho, es la primera vez que, en un film de Pedro Almodóvar, la televisión tiene un rol positivo, eso sí, gracias a una censura férrea, ya que Vera sólo tiene acceso a tres canales. Con todo, estas pantallas tienen como efecto principal poner en contacto diferentes espacios y diferentes personajes; son a la vez un marco, es decir un continente que delimita la imagen, una interfaz

11 "Dans ces moments intimes d'étroite surveillance, bien que Vera soit la victime, il émane de son visage démesuré un immense pouvoir, bien plus grand que celui du Dr Ledgard qui la contemple, extasié".

${ }_{12}$ La analogía harto conocida entre la hipnosis y el dispositivo cinematográfico ha sido recientemente reconsiderado y profundizado por Raymond Bellour (Bellour, 2009).

203 
entre el interior y el exterior, una barrera de protección y un filtro de intercambios. Reconocemos aquí las tres funciones de base del Yo-Piel (el saco, la pantalla y el tamiz), aplicables a estas pantallas de plasma que nos permiten establecer una analogía entre la pantalla y la piel, un paralelismo entre lo visual y lo táctil. Esta relación se ve plasmada mediante un plano de una obscenidad poco común en el que Zeca, creyendo reconocer a Gal en Vera, lame la pantalla de control. Ya, en su obra anterior, Los abrazos rotos, Pedro Almodóvar hacía que su protagonista masculino ciego, Mateo Blanco, acariciara una pantalla y expresara así su "propio deseo de tocar el cine con [sus] manos"13, este "ideal del espectador que pudiera entrar en contacto con el film mediante su cuerpo entero"14. Aunque tengan implicaciones muy diferentes, dichos planos dicen la imposibilidad de acceder a la imagen de otro modo que con la mirada, al tiempo que dan cuenta de una forma de transferencia sinestésica entre la mirada y el tacto, transferencia que la metáfora de la pantalla como piel nos puede ayudar a considerar.

Deleuze desarrolló, en su reflexión acerca de la pintura, entre otra la de Bacon, la idea de que "la visión misma descubr[e] en sí una función de tacto que le es propia, y sólo de ella, distinta de su función óptica"15. Esta "función de tacto" que posee la mirada, la califica de háptica siguiendo a Aloïs Riegl quien elaboró el término a partir del griego hapten que designa a la vez el tacto y el vínculo; la función háptica es posible gracias a una visión de proximidad, sin profundidad visual, en la que el ojo fusiona con la imagen y ésta se desborda sobre el espectador (Riegl, 1978); Deleuze la opone a la visión óptica que abarca un espacio lejano, organizado y jerarquizado por la perspectiva. Aunque, por supuesto, domina en el cine la visión óptica, ambas funciones estéticas, óptica y háptica, alternan por las variaciones de escalas de planos en las que el primerísimo plano y el inserto pueden modificar las dimensiones de un detalle hasta la abstracción, y donde el grano de la imagen

13 "[...] l'expression de mon propre désir de pouvoir toucher le cinéma avec mes mains", (Ciment y Rouyer, 2009: 11).

14 "[...] un idéal du spectateur qui pourrait entrer en contact avec le film à travers tout son corps" (Ciment y Rouyer, 2009: 11).

15 " la vue elle-même découvr[e] en soi une fonction de toucher qui lui est propre, et n’appartient qu'à elle, distincte de sa fonction optique » (Deleuze, 1981: 146).

204 
y su textura pueden invadir la totalidad del espacio espectatorial, creando lo que Deleuze nombra un "absoluto de la presencia" (Deleuze, 1980, 616). Esta mirada abarcadora aniquila la distancia entre el ojo y el objeto mirado. La visión háptica toca con la mirada (en el lenguaje común se acaricia o se envuelve con la mirada), establece una relación en la que la mirada se hace contacto al sumergirse en el objeto mirado dando la sensación de palpar una materia.

La transferencia sinestésica es particularmente frecuente en el cine donde el espectador, cautivo consentido, reacciona a menudo a flor de piel a ciertos estímulos visuales desagradables (los primerísimos planos de inyecciones bastan para comprobarlo) que reactivan una memoria de experiencias táctiles y provocan reacciones físicas. Un plano detalle del grano de la piel (como vemos cuando Ledgard hace un zoom sobre la espalda desnuda de Vera) puede, a la inversa, dar una sensación de suavidad, de calor, de liso, de redondo. El espectador intradiegético (Ledgard) tanto como el extradiegético (nosotros) queda atrapado por la imagen, la toca con la mirada al tiempo que es tocado por ella.

La frecuencia de planos detalle en el cine de Pedro Almodóvar parece encontrar en La piel que habito una justificación estética en la que la importancia concedida a la mano y al tacto viene a corroborar la preeminencia háptica de ciertos espacios fílmicos. En efecto, la omnipresencia de primeros planos de manos cosiendo, modelando, escribiendo, acariciando, revistiendo guantes no remite sólo a actividades manuales sino también al sentido háptico de la visión.

Para Riegl, el artista, concretamente el pintor y el escultor, es ante todo una mano. Obviamente no se puede decir lo mismo de un cineasta, quien es ante todo un ojo, sin embargo, la insistencia sobre la costura y el trabajo del tejido, tanto epidérmico como textil, sugiere un acercamiento entre todas las operaciones, - en los múltiples sentidos de la palabra -, que tienen lugar en el interior del film, y el trabajo del cine mismo como arte del ensamblaje y de la sutura (es uno de los principales temas de Los abrazos rotos) (Brémard, 2011, 43-56). Se puede considerar, en efecto, que el doctor Ledgard es un 
alter ego del director que va creando sus películas y personajes pieza a pieza, sin vacilar en recurrir a fragmentos fílmicos exógenos.

Las prácticas transtextuales del cineasta son harto conocidas y no duda en reivindicarlas como formas de saqueo y no de homenaje: "Todas las películas que aparecen en las mías quedan meticulosamente escogidas, forman parte del guión en el que desempeñan un papel activo. No son homenajes sino auténticos robos, me adueño de los filmes en beneficio de la historia que voy contando"16. Analicé en otro lugar en qué medida el motivo del transplante de órganos tal como aparece en La flor de mi secreto y Todo sobre mi madre puede servir de paradigma a cómo Pedro Almodóvar injerta en sus películas órganos o tejidos fílmicos procedentes de otras películas (Thibaudeau, 2003, 195-211). Si se puede considerar que La piel que habito viene confirmando este modelo, las referencias, por visibles que sean, se encuentran más imbricadas y diseminadas, y no hay citas directas, con excepción de algunos planos de un corto metraje experimental en blanco y negro ${ }^{17}$, Endless not, entrevisto en la televisión de la habitación de Vera. El film reactiva sin embargo la memoria de otras películas como Los ojos sin rostro de Georges Franju, Frankenstein de James Whale, Vértigo y Rebecca de Alfred Hitchcock cuyas intrigas, situaciones y relaciones de fuerza entre personajes parecen nutrir La piel que habito. Este arte del ensamblaje radica tanto en la cirugía como en la costura y el collage; así lo sugiere el juego de correspondencias instauradas por el filme entre todas estas prácticas

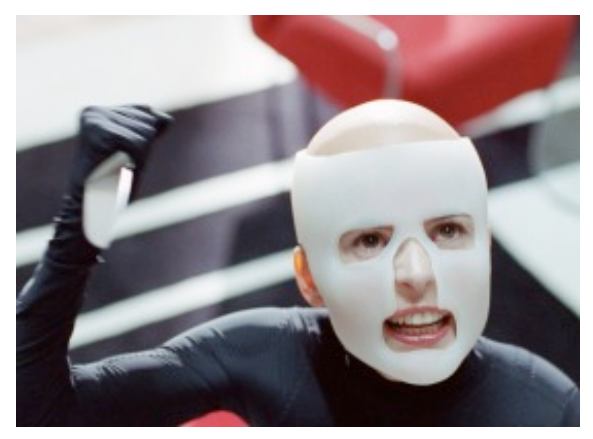
manuales. Otros recuerdos surgen en el transcurso de un plano, de una imagen furtiva, Tristana de Luis Buñuel (con el gran plano general de Toledo que inaugura la película), Persona de Ingmar Bergman (con el niño acariciando los rostros femeninos que van apareciendo uno tras

\footnotetext{
16 «Tous les films qui apparaissent dans les miens sont méticuleusement choisis, ils font partie du scénario, ils y jouent un rôle actif. Ce ne sont pas des hommages mais bel et bien des vols, je m'approprie leurs films au bénéfice de l'histoire que je raconte », (Almodóvar, 2005).

${ }^{17}$ Se trata de Endless not (2008) de Oscar Shocking.
} 
otro sobre una pantalla), pero también Fantomas o Judex (el body negro y la máscara que lleva Vera un tiempo -F 7), sin hablar de las películas del mismo Pedro Almodóvar: Todo sobre mi madre (planos de quirófanos), Hable con ella (las estatuas yacentes), Kika (la criada atada en la cocina), etc. células extraídas de otro organismo e inyectadas en uno nuevo.

Todos estos elementos tomados prestados de otras películas, ensamblados, injertados, cosidos van componiendo un cuerpo fílmico híbrido pero nuevo y único, hacia donde convergen los territorios de la piel, del lienzo y la pantalla. Vera ha sido creada a partir de la metamorfosis de Vicente, es una forma compuesta en la que interfieren el cuerpo de un hombre mutilado, los órganos artificiales de una mujer, el rostro reconstituido de una muerta y, envolviéndolo todo, una piel transgénica, fruto de la confluencia de células humanas y animales. Bajo la perfección plástica de su cuerpo y de su cara, Vera es un monstruo, de la misma manera que la criatura creada por Frankenstein o las otras películas de un cineasta que hizo del reciclaje y el palimpsesto la condición misma de su arte. Como subraya él mismo ${ }^{18}$, ċacaso no se utiliza la palabra "monstruo" para designar el primer montaje de los planos de un filme, ese estado que precede cualquier búsqueda de ritmo y armonización?

El cuerpo original de Vicente ha desaparecido, pero el de Vera conserva su memoria, y les corresponde a sus familiares (su madre, Cristina) reconocer en ella lo que fue. Del mismo modo, la envoltura fílmica final que revistió el monstruo no deja de conservar la memoria de lo que lo constituyó, y le corresponde al espectador volver a encontrar las huellas, pero siguiendo los consejos que le da el cineasta mediante la profesora de yoga dirigiéndose a los televidentes: "Hay que tener cuidado, no obstante, de no confundir asâna, la forma, con el fondo", es decir, tanto para el yoga, como para Vicente y el film, no hay que confundir la apariencia externa de las posturas (asâna) y de las formas con la verdad interior a la que permite acceder.

18 "El montaje se parece efectivamente a una operación quirúrgica. De hecho, en España, se suele llamar "el monstruo" el primer montaje de todas las escenas de un film, una tras otra" ("Le montage ressemble effectivement à une opération chirurgicale. D'ailleurs, en Espagne, nous appelons "le monstre" le premier montage qui est le bout-à-bout de toutes les scènes d'un film") (Ciment y Rouyer, 2011, 12). 


\section{Referencias bibliográficas}

Almodóvar, Pedro (2005). Exhibition, Catalogue. Paris: Les Éditions du Panama, La Cinémathèque Française.

Anzieu, Didier (1985). Le Moi-Peau. Paris: Dunod, 1995, $2^{\text {da }}$ edición aumentada.

Bellour, Raymond (2009). Le corps du cinéma. Paris: P.O.L.

Brémard, Bénédicte (2011). Les étreintes brisées (Almodóvar) : palimpsestes d'outre-tombe ? En Bénédicte Brémard, Julie Michot, Marc Rolland, Carl Vetters, L'écran palimpseste: cinéma et intertextualité, Les Cahiers du Littoral I/ ${ }^{\circ}{ }_{12}$, Shaker Verlag, pp. 43-56.

Brémard, Bénédicte (2012). La piel que habito: la nueva silfida de Almodóvar. En Image et genre, Actas del $8^{\circ}$ congreso Internacional del Grimh, 15-17 de noviembre de 2012 (publicación prevista en 2014).

Ciment, Michel y Rouyer, Philippe (2009). Entretien avec Pedro Almodóvar. Filmer avec passion des personnages d'une grande intensité. En Positif, $\mathrm{n}^{\circ}$ 579, mai.

Ciment, Michel y Rouyer, Philippe (2011). Entretien avec Pedro Almodóvar. Un film de terreur au plus près du quotidien. En Positif, $\mathrm{n}^{\circ} 607$, septembre.

Deleuze, Gilles (1980). Mille plateaux. Paris: Editions de Minuit.

Deleuze, Gilles (1981). Francis Bacon. La logique de la sensation. Paris: Seuil (1972).

Duncan, Paul y Peiró, Barbara (dir.) (2011). Les archives Pedro Almodóvar. Cologne: Tashen.

Riegl, Aloïs (1978). Grammaire historique des arts plastiques, (trad. Eliane Kaufholz). Paris: Klincksieck.

Seguin, Jean-Claude (2009). Pedro Almodóvar, o la deriva de los cuerpos. Murcia: Tres fronteras ediciones.

Storr, Robert (1992). Géométries intimes: l'œuvre et la vie de Louise Bourgeois. En Art Press, ${ }^{\circ}$ 175, déc.

Thibaudeau, Pascale (2003). Greffes et transplantations de tissus filmiques : une métaphore à la manière de Pedro Almodóvar. En Véronique Campan y Gilles Ménégaldo (dir.), Du maniérisme au cinéma, La Licorne. Poitiers: MSHS, pp. 195-211.

Thibaudeau, Pascale (2014). De un cuerpo a otro: la espera del sujeto. En La piel que habito de Pedro Almodóvar. Ámbitos (Córdoba) (en prensa). 